\title{
Improved Wait Times from Abnormal Diagnostic Imaging to Biopsy of Suspicious Breast Lesions at King Abdulaziz University Hospital
}

\author{
Laila K. Ashkar, MBBS, FRCP(C), ABR \\ Department of Radiology, Faculty of Medicine, King Abdulaziz University \\ Jeddah, Saudi Arabia
}

\section{Correspondence}

Dr. Laila K. Ashkar

P.O. Box 80215

Jeddah 21589, Saudi Arabia

e.M:lashka@gmail.com

\section{Submission: 07 August 2017}

Accepted: 29 August 2017

\section{Citation}

Ashkar LK. Improved wait times from abnormal diagnostic imaging to biopsy of suspicious breast lesions at King Abdulaziz University Hospital. JKAU Med Sci 2017; 24 (4): 15-20. DOl: 10.4197/Med. 24.4.3

\begin{abstract}
Timely coordinated breast biopsies following abnormal diagnostic breast imaging reduces patient anxiety and may optimize breast cancer prognosis. Two different pathways have been used in the breast unit at the Radiology Department of King Abdulaziz University Hospital. Before September 2009, all patients who had abnormal breast imaging were sent back to their referring physician, who would then request the necessary biopsy. In September 2009, we proposed the shortened pathway; and coordinated the necessary biopsy directly at our unit, instead of sending the patients back to their physician. This has saved them many weeks of agony and confusion navigating through the medical system to arrange appointments for surgical consultation and radiological biopsy. This study aimed to assess the wait time from abnormal breast imaging to the time of the biopsy. A retrospective study included an analysis of 51 consecutive breast biopsies performed before 2009, compared to 51 biopsy patients after implementing the improved pathway in 2009. It concluded that the expedited pathway reduced the wait time from 42 to 14 days until final diagnosis. To ensure that targets for timeliness are realized, this improved and efficient pathway of care was adapted permanently and has been ongoing since then.
\end{abstract}

\section{Keywords}

Wait time to breast biopsy; Breast biopsy anxiety; Timeline biopsy

\section{Introduction}

$P$ ractice guidelines for breast cancer emphasize that the work-up of an abnormality in the breast should be completed as soon as possible after detection. Given the substantial importance of screening and early detection of breast cancer, one would expect a similar emphasis on early diagnosis by biopsy, which would further impact prognosis.
In a number of publications from Canada, Germany and the United Kingdom, time intervals between care steps in the diagnosis, management and treatment of breast cancer have been evaluated ${ }^{[1]}$. Some of these studies have focused on time to first surgical intervention ${ }^{[2]}$ while others from time to pathological confirmation of invasive disease ${ }^{[3]}$. 
"A recent meta-analysis of data from 87 nonexperimental studies involving over 100,000 patients concluded that women who delayed seeking medical attention for 3 months or more had a 12\% lower 5-year survival rate than those who presented sooner (odds ratio 1.47; 95\% confidence interval $[\mathrm{Cl}]$ 1.42 to 1.53$)^{\prime \prime}[2]$.

The continuum of care for potentially curable breast cancer, however, has become increasingly complex and multidisciplinary. Patients interact with a number of various health care professionals and attend a series of appointments at several departments or in different areas of a large hospital[ ${ }^{[4]}$. Delays can arise if a woman should navigate from one place to another to arrange the appointments with her referring physician, who then will ask her to return to the radiology department to arrange for her breast biopsy. For the patients, this pathway means additional wait time and anxiety until final diagnosis.

"The development of comprehensive breast centers, which arrange expedited biopsies, is an effective means of streamlining the management of patients with abnormalities detected through abnormal imaging, by minimizing the number of visits and decreasing the overall waiting time and expedite final diagnosis" ${ }^{15,6]}$.

Although a critical component in breast cancer care is the time from abnormal breast imaging results to completion of the breast biopsy, it has not been studied extensively in previous analyses of elapsed times in breast cancer care.

The objective of this study was to document the elapsed time from first radiological detection of a breast abnormality to completion of the breast biopsy in women with invasive breast cancer, who were referred by surgeons, before and after introducing the improved and expedited pathway in September 2009.

\section{Materials and Methods}

The retrospective study was carried out at the breast unit of the radiology department at King Abdulaziz University Hospital in Jeddah, Saudi Arabia, and included an analysis of 106 newly diagnosed women with breast cancer who underwent breast biopsies. Fifty-one consecutive biopsies were performed before introducing the expedited pathway in September 2009, and then compared to 51 patients who were biopsied after implementing the improved pathway. Eligible women were all women who underwent a breast biopsy during that period. The wait time was calculated from the date of abnormal imaging to the date of the biopsy. All dates were retrieved from patient's electronic charts and the breast biopsy logbooks. All time intervals were calculated in days.

Prior to September 2009, women had to return to their referring physician to be notified about the abnormal radiological result, who would then send the patient back to radiology to schedule the appointment for the subsequent necessary biopsy. This wait-time was calculated and compared to the patient's wait time after September 2009, who had their necessary biopsy coordinated and directly arranged at our breast unit, instead of being sent back to their physician. This has saved them many weeks of agony and confusion navigating through the medical system to arrange appointments for surgical consultation and radiological biopsy.

The core biopsy was defined as one performed after informed consent and aseptic technique, under targeted ultrasound guidance with a "BARD ${ }^{\circledR}$ MAX-CORE ${ }^{\circledR}$ Disposable Core Biopsy Instrument 14-gauge spring loaded biopsy needle (Bard Biopsy Systems, Tempe, $A Z)$ ", and the patient was discharged on the same day. The patient was then asked to visit her referring physician to review and discuss the final pathology results.

\section{Results}

A total of 106 newly diagnosed women with breast cancer who underwent breast biopsies were included over the study period before and after September 2009. Of the 106, 102 met the inclusion criteria, 51 patients before and 51 patients after September 2009 were eligible for analysis.

The different steps from the patient's visit to the physician at the clinic, to referral to radiology, the wait time for a radiology appointment, imaging and interpretation, and the time between interpretation and referral of patients back to the clinician, and the wait time for the scheduled follow-up biopsy procedure, were all assessed (Diag. 1). These numerous steps and timelines were calculated and compared for cancer patients who underwent breast biopsies before and after introduction of the expedited pathway in September 2009 (Diag. 2). 
Data analysis was done using SPSS Statistics for Windows, Version 17.0. (SPSS Inc., Chicago, IL USA). The average time interval from radiological cancer detection to initiation of biopsy was 42.63 days prior to September 2009, and improved to a wait time of 14.5 days, after the introduction of the expedited pathway in September 2009 (Fig. 1). This was calculated as a percentage of improvement of $58.8 \%$.

\section{Discussion}

One of the most crucial key indicators of a health's system performance are waiting times. "In the United States, about one in five of screened women who are recalled, will receive a recommendation for biopsy. How promptly such recall to further evaluation, including biopsy, is conducted is crucial to a program's success.

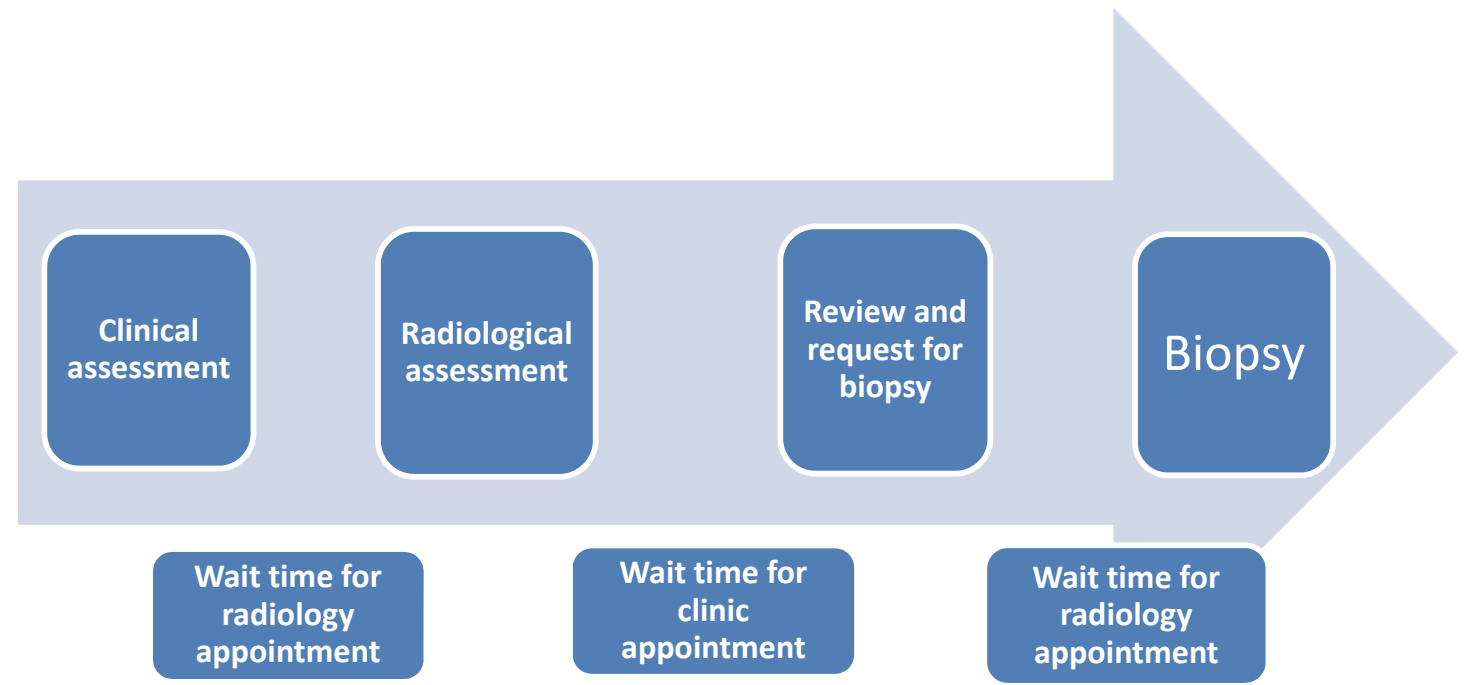

Diagram 1. Multiple extra steps and time wasted for patients from initial clinic visit to arranging several appointments for required radiological studies until biopsy diagnosis.

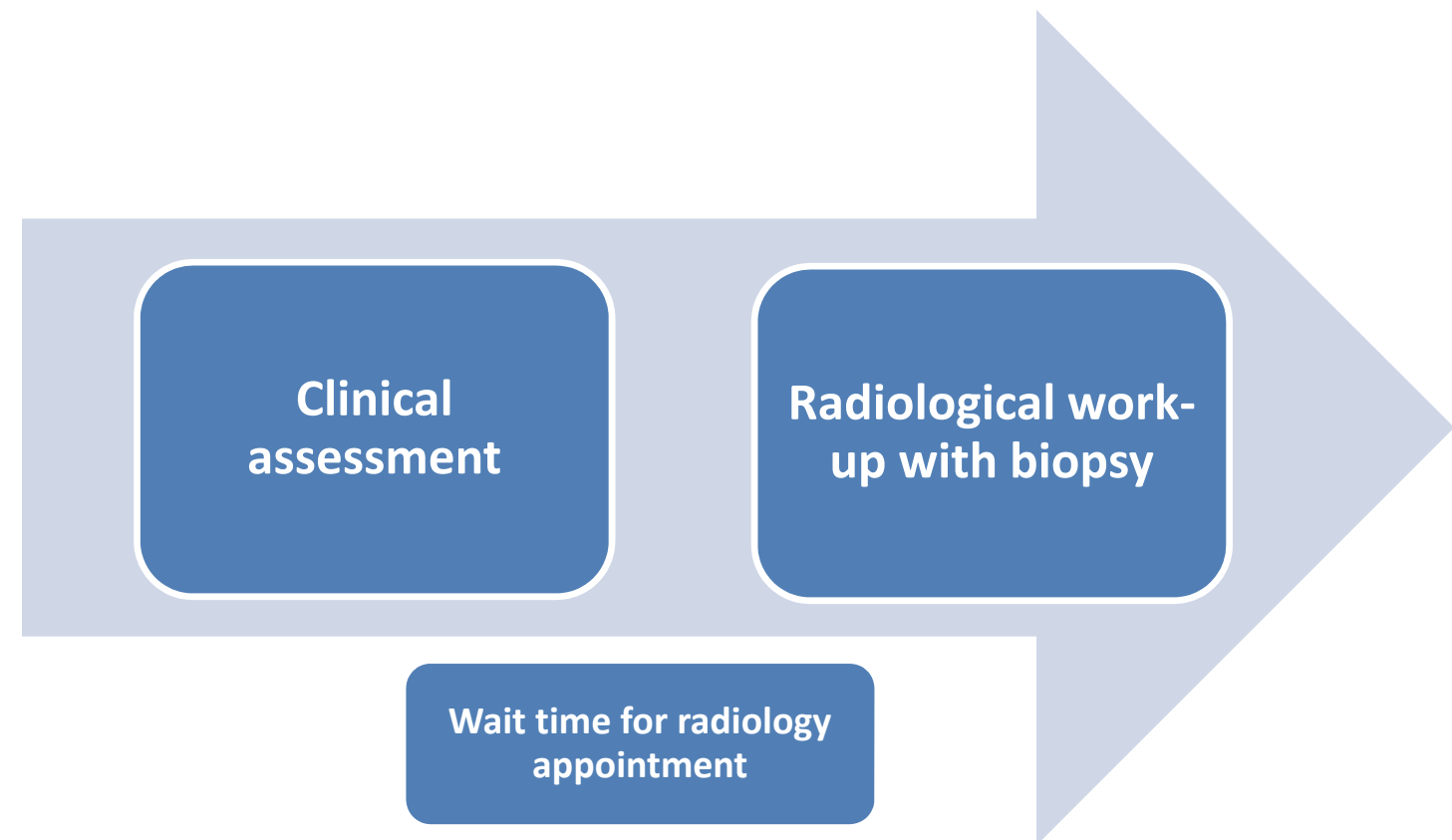

Diagram 2. The visits to the referring physician in between diagnostic imaging studies and biopsy have been eliminated after agreement with surgeons, thereby expediting the patient's diagnostic biopsy with shortened wait time. 


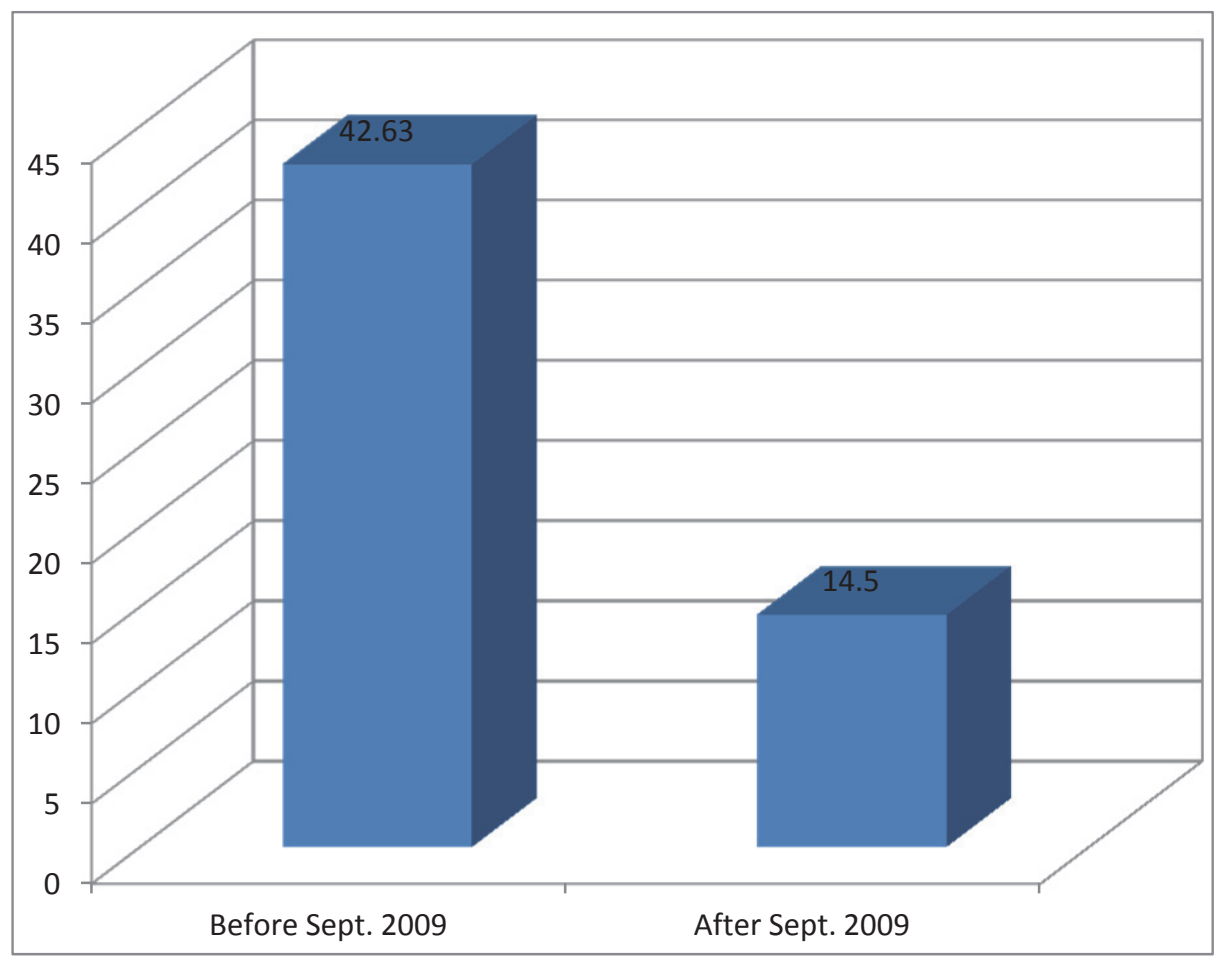

Figure 1. Wait time from abnormal breast imaging to breast biopsy.

Prompt evaluation minimizes a patient's anxiety in regard to an abnormal screening mammogram" ${ }^{\prime[7]}$.

Based on expert consensus, the European community has published their recommended guidelines for timeliness of follow-up ${ }^{[8]}$, and to our knowledge, they are the only such published guidelines. The recommendations of the fourth edition of the European guidelines ${ }^{[8]}$ are "that women be notified and that any biopsy occurs within 15 days of being offered after an abnormal radiological breast imaging work-up, however, there is wide variation and room for improvement"[7].

Because diagnostic imaging work-up involves multiple steps and sometimes multiple facilities, delays may occur in many places, and therefore, each facility needs policies tailored to its circumstances. When diagnostic breast imaging is obtained at the radiology facility, delays may occur between imaging and interpretation, between interpretation and referral of patients to the clinician, and between patient contact and the date of the scheduled biopsy procedure ${ }^{[9]}$.

Image-guided needle biopsy logistics often require coordination between radiology, surgery and the patient, substantially complicating and possibly delaying the process. An optimal system would minimize the time required to complete the biopsy process for final diagnosis-and thus minimize patient anxiety ${ }^{[7]}$. A persistent concern is also how these delays affect women's satisfaction and use of subsequent screening. "An abnormal imaging result and the need to undergo subsequent biopsy may cause morbidity that includes, but is not limited to, an acute increase in anxiety and the discomfort, time and expense of additional tests. These adverse effects should be reduced by providing timely follow up that assures a firm diagnosis with the minimum number of steps" ${ }^{\prime[3]}$.

The improvement in the timeliness at our institute before and after September 2009 was due to our assistance in navigating women through the diagnostic process on behalf of the referring clinician, and arranging the required biopsy directly for them.

The development of all-inclusive dedicated breast centers is an effective means of streamlining the management of patients with abnormalities detected through clinical or radiological examination, by minimizing the number of visits and decreasing the overall waiting time to final diagnosis ${ }^{[4]}$. 


\section{Conclusion and Recommendation}

In conclusion, time to follow-up differs widely between facilities, suggesting potential for improvement by many institutes. Better scheduling of diagnostic tests and treatment propositions should improve waiting times in the management of breast cancer ${ }^{[10]}$.

Women with abnormal breast imaging require diagnostic assessment and experience anxiety until a final diagnosis is established. Even within effective systems, correctible communication issues may adversely affect time to diagnosis. To ensure that targets for timeliness are realized, improved models of care, better scheduling, organized assessment, efficient techniques and expedited steps to reach a diagnosis will be needed.

Physicians providing cancer care are uniquely positioned to help women navigate through barriers of the medical system. Knowledge of factors associated with delays is valuable for planning interventions and allocating program resources.

\section{Acknowledgments}

I thank the participating women, radiology facility, and radiologists for the data they provided for this study. I also thank Dr. Maram Aljuaid who participated in data collection and statistical analysis.

\section{Conflict of Interest}

The author has no conflict of interest.

\section{Disclosure}

The author did not receive any commercial or financial support for this study. The author has no financial interest in any of the products, devices, or drugs mentioned in this article.

\section{Ethical Approval}

Obtained.

\section{References}

[1] Rayson D, Chiasson D, Dewar R. Elapsed time from breast cancer detection to first adjuvant therapy in a Canadian province. 1999-2000. CMAJ 2004; 170(6): 957-961.

[2] Mayo NE, Scott SC, Shen N, Hanley J, Goldberg MS, MacDonald N. Waiting time for breast cancer surgery in Quebec. CMAJ 2001; 164(8): 1133-1138
[3] Olivotto IA, Bancej C, Goel V, Snider J, McAuley RG, Irvine B, Kan L, Mirsky D, Sabine MJ, McGilly R, Caines JS. Waiting times from abnormal breast screen to diagnosis in 7 Canadian provinces. CMAJ 2001; 165(3): 277-283.

[4] Pasteur Rasuli. Breast cancer diagnosis: What are we waiting for? CMAJ 2001; 165(3): 303-304.

[5] Parker S, Tomaselli MB. Streamlining breast disease management. J Healthc Resour Manag 1996; 14(7):: 23-26.

[6] Rouex S, Logan-Young W. Private practice interdisciplinary breast centers: their rationale and impact on patients, physicians, and the health care industry: a bicoastal perspective. Surg Oncol Clin N Am 2000; 9(2):: 177-198.

[7] Rosenberg RD, Haneuse SJ, Geller BM, Buist DS, Miglioretti DL, Brenner RJ, Smith-Bindman R, Taplin SH; Breast Cancer Surveillance Consortium. Timeliness of follow-up after abnormal screening mammogram: variability of facilities. Radiology 2011; 261(2): 404-413.

[8] Perry N, Broeders M, de Wolf C, Törnberg S, Holland R, von Karsa L. European Guidelines for Quality Assurance in Breast Cancer Screening and Diagnosis. Fourth edition. Luxembourg: Office for Official Publications of the European Communities, 2006; 187: 188-213.

[9] Zapka J, Taplin SH, Price RA, Cranos C, Yabroff R. Factors in quality care: the case of follow-up to abnormal cancer screening tests-problems in the steps and interfaces of care. J Natl Cancer Inst Monogr 2010; 2010(40): 58-71.

[10] Molinié F, Leux C, Delafosse P, Ayrault-Piault S, Arveux P, Woronoff AS, Guizard AV, Velten M, Ganry O, Bara S, Daubisse-Marliac L, Tretarre B. Waiting time disparities in breast cancer diagnosis and treatment: a populationbased study in France. Breast 2013; 22(5): 810-816. 


\title{
خفض أوقات الانتظار من التصوير التشخيصي غير الطبيعي إلى حين إجراء خزعة كتلة الثدي المشبوهة في مستشفى جامعة الملتك عبدالعزيز الطيز
}

\author{
ليلى خالد أشقر \\ قسم الأشعة، كلبة الطب الطب

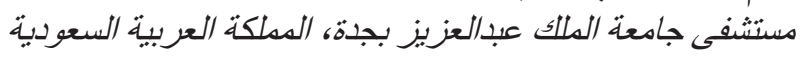

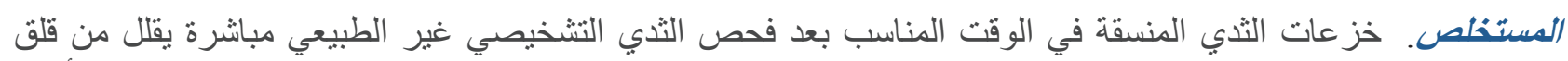

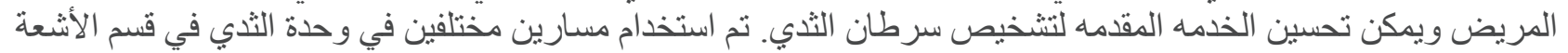

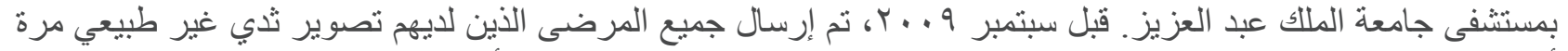

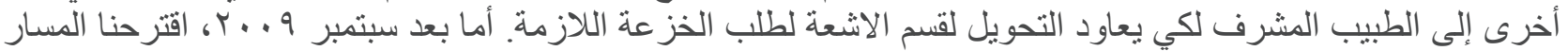

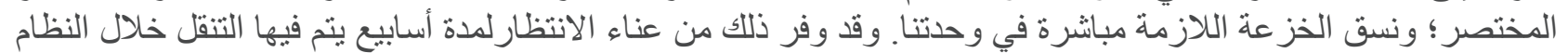

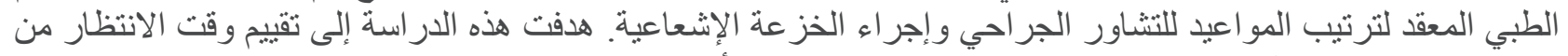

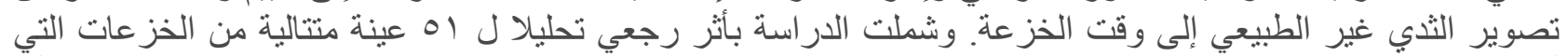

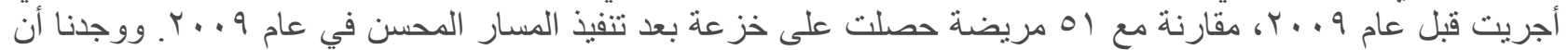

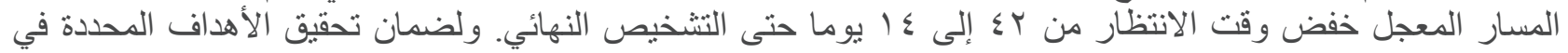
الوقت المناسب، جرى تعديل مسار الرعاية المحسنة بشكل دائم، وهو مستمر منذ ذلك الكئ الحين. 